NBER WORKING PAPER SERIES

GROWTH, TECHNOLOGICAL PROGRESS, AND TRADE

E1hanan Helpman

Working Paper No. 2592

NATIONAL BUREAU OF ECONOMIC RESEARCH 1050 Massachusetts Avenue

Cambridge, MA 02138

May 1988

The research reported here is part of the NBER's research program in International studies. Any opinions expressed are those of the authors and not those of the National Bureau of Economic Research. 
NBER Working Paper \#2592

May 1988

Growth, Technological Progress, and Trade

\title{
ABSTRACT
}

\begin{abstract}
Recent developments in the theory of economic growth and dynamic trade theory are reviewed and interpreted. These include growth based on economies of scale, trade with product development, and product cycles. It is argued that there is need for more work in this area in order to understand the relationship between trade and growth.
\end{abstract}

Elhanan Helpman Department of Economics Tel Aviv University Tel Aviv, Israel 
Revised: March 1988.

\section{GROWTH, TECHNOLOGICAL PROGRESS, AND TRADE}

by

Elhanan Helpman ${ }^{1}$

Tel Aviv University and MIT

\section{Introduction}

This paper deals with the relationship between international trade and economic growth. It deals, therefore, with an old question, but also a question in search to a new answer. The renewed interest in this subject has arisen as a result of a combination of events, research results (or more to the point, a lack of satisfactory research results), and the availability of new tools. As far as events are concerned, there is the decline of output growth in the 1970 s that was associated with a productivity slowdown. During those years the volume of world trade declined for the first time since World War II. Despite the general slowdown, however, some counties managed to maintain relatively high growth rates. For example, the average rate of growth of the four Asian NICs--Korea, Hong-Kong, Taiwan and Singapur--remained at the high average level of 8.3 percent per annume during 1973-1984. This

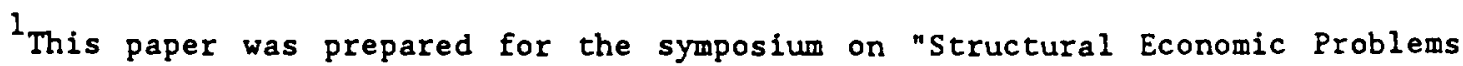
and International Trade" that was organized by the Confederation of European Economic Associations and was held in Hernstein, Austria, on March 2-4, 1988. I would like to thank Gene Grossman for allowing me to use insights from our joint ongoing work in the preparation of this paper, and to Paul Romer and Martin Weitzman for comments on an earlier draft. 
raises the question: Why were some countries painfully affected by the adverse shocks to the world economy while others have avoided much of the damage? Naturally, an answer to this question--which refers to a particular episode-requires a detailed understanding of the episode itself. But a reliable answer also requires an understanding of the broad forces of economic growth and their relationship to international trade. This is the more so in view of the fact that as a rule, output growth is often strongly correlated with export growth (see Michaely (1977), Feder (1982), and Helpman and Trajtenberg (1987)). For example, during the years of the slowdown 1973-1984 exports of Korea and Taiwan grew at an average rate of about 15 percent.

The traditional approach to economic growth as a process of capital accumulation has provided important insights, but failed to provide a satisfactory account of the data. This brought about a shift of attention to technical progress. Viewed in broad terms, technical progress should be able to explain the residual in growth accounting. It is, however, an illusive term that needs to be filled up with concrete details in order to be useful, and this has proved to be a difficult task (see Grilliches (1979)). Recent developments in the theory of industrial organization, which treat explicitly research and development and economies of scale, may help to fill in this gap. On the other hand, the theory of international trade has been influenced by advances in industrial organization for close to ten years. However, the major bulck of work in this area was static. The recent revival of interest in dynamic trade issues provides an opportunity to extend this work in order to deal with dynamic trade issues. It may prove helpful in explaining the long-run relationship between trade and growth. We need a theory that can address fundamental questions, such as: Does growth drive trade or is there a reverse link from trade to growth? Many authors have emphasized the role of 
free trade in promoting growth (see, for example, Bhagwati (1978) and Krueger (1978)). Nevertheless, there also exist arguments that trade policy was central in the promotion of fast growth in Japan and some of the NICs. Current theory is not sultable to deal in a satisfactory way with these alternative views.

Then there exists the question of the determinants of long-run growth. Neoclassical theory predicts declining growth rates, unless there is technical progress. On the other hand, growth rates of the most advanced countries have not been declining, and growth rates seem to be positively autocorrelated (see Romer (1986)). Moreover, developed countries grow on average faster than less developed countries. Does it indicate that there are no diminishing returns to growth? And how is all this related to trade?

There is, of course, a debate concerning the proposition that productivity levels converge. Baumol (1986), for example, has argued that they do (see also Maddison (1987)). However, his sample of countries--that builds on Maddison's (1982) data set--suffers from a sample selection bias that leads to this conclusion even if the proposition is wrong. More careful examination of the data suggests that convergence of productivity levels is at least doubtful (see De Long (1987) and Romer (1988). Is international trade an important element in these processees? Some observers belive that it is, and that international learning goes far beyond direct trade relationships (see, for example, Pasinetti (1981, chap. XI)).

I cannot offer answers to all these and other related questions. What I can offer instead is a description of some recent work which helps to think in novel ways about them. Some of this work is exploratory in nature; most of it is rather fragmented. It nevertheless has a lot in common, as I will try to explain, and may eventually lead to a coherent theory. This is an exciting 
renewed area of enquiry. I will start with a brief description of the neoclassical aggregative approach to growith in order to set up the stage for the following discussion. I will then proceed to discuss new lines of work on the theory of economic growth that emphasize economies of scale. These studies deal with closed economies, but $I$ will also discuss their implications for the role of international trade. This will be folloed by a description of a disaggregated approach in which trade figures prominently. Finally, I will deal with the role of product cycles which have not yet been integrated into this line of research--a task awaiting to be done.

\section{Aggregative Approach}

Every theory of economic growth builds on the saving-investment relationship. It is therefore possible, at least in principle, to build a theory in which the main driving force is either saving or investment. The neoclassical theory underlines the role of saving, in the sense that it emphasizes the desire to allocate consumption over time, making investment respond to the consumption needs. I will therefore concentrate on growth in consumption per capita. Since the role of population growth is well understood in these frameworks, I abstract from population growth altogether. With this clarification in mind, we can formulate the consumption choice problem that is at the heart of neoclassical growth theory as follows:

$$
\max \int_{0}^{\infty} e^{-\rho t} u[c(t)] d t
$$

subject to the intertemporal budget constraint 


$$
\int_{0}^{\infty} e^{-R(t)} c(t) d t=\Omega,
$$

where $\rho$ is the subjective discount rate, $u(c)$ is the temporal utility function, $c$ is consumption, $R(t)$ is the discount factor, $\Omega$ is wealth at time zero, and $t$ is a time index. Wealth at time zero is defined as the value of existing assets plus the present value of income from nonmarketable assets (such as labor income). The wealth level is taken to be exogenous by the individual consumer, but it is in fact endogenous to the economy at large; it depends on the time pattern of wages, technological factors, and the like. Similarly for the interest factor; it is exogenous to the individual consumer but endogenous to the economy (in the context of international economics the interest factor might also be exogenous to a single country--the small country assumption--but it is endogenous to the world economy). A major difficulty in the derivation of a complete characterization of equilibrium trajectories is Indeed the solution of variables that are exogenous to the individual decision maker but endogenous to the economy.

The solution to the consumer's problem yields the following equation for consumption growth:

$$
\frac{\dot{c}}{c}=\beta(r-\rho)
$$

where $\beta$ is the inverse of the elasticity of the marginal utility of consumption, defined to be positive, and $r=\dot{R}$ is the instantaneous real interest rate. This is the fundamental equation that $I$ will use to discuss aggregative growth. It implies that positive growth requires the real interest rate to be larger than the subjective discount rate. Since the subjective discount rate is taken as an exogenous constant, issues of growth 
become inseparabie from factors that determine the real interest rate and : is change over time. In order to concentrate on the main issues, I now assume that the elasticity of the marginal utility of consumption is constant, which amounts to assuming an isoelastic utility function.

The fundamental growth equation (1) reveals a great deal about what is possible in frameworks that rely on it. For one thing, it shows that sustained long-run growth is possible only if the real interest rate can be maintained above the subjective discount factor. But the behavior of the real interest rate is related to the technology of production and accumulation. Therefore the possibilities of sustained long-run growth depend on the nature of these technologies.

In the one-sector neoclassical model output $y$ is a concave function of the capital stock $k$ (the constant labor supply is suppressed): $y-f(k)$. Abstracting from adjustment costs in capital formation, suppose that a unit of output can be converted into one unit of capital. Then at each point in time the cost of a unit of capital is 1 (in terms of output, which is the numeraire). On the other hand, without depreciation the return to the ownership of a unit of capital is the entire future stream of its marginal product value (it is also possible to specify this relationship by taking explicit account of the possibility of resale of the capital unit), with this stream depending on the time path of the economy's capital stock. No capital accumulation takes place when current costs exceed the present value of the return (assuming irreversibility of investment; otherwise divestment will take place). If, however, capital accumulation does take place at a point in time $t$, or it is just marginally profitable to invest, then the current value of a unit of capital, which is 1 , is equal to the present value of its marginal product value, 


$$
\int_{t}^{\infty} e^{-[R(\tau)-R(\tau)]} f_{k}[k(\tau)] d \tau-1 .
$$

In a competitive equilibrium the left-hand side of (2a) cannot exceed 1 .

Equation (2a) represents a standard asset pricing equation. In the context of growth it provides a link between the real interest rate and capital accumulation. Differenifation with respect to time yields

$$
r(t)-f_{k}[k(t)] \text {, }
$$

namely, the real interest rate is equal to the marginal product of capital (the presence of adjustment costs generates a more complicated relationship). Since capital accumulation reduces the marginal product of capital, it also leads to a declining real interest rate. Therefore, capital accumulation cannot lead to sustained long-run growth; it leads to declining real interest rates, and when the real interest rate becomes equal to the subjective discount rate consumption growth ceases and the economy reaches a steady state. The long-run interest rate is equal to the subjective discount rate.

These results have certain implications for a system of countries. In a world economy in which there exist no international capital movements countries will grow at independent rates, as determined by their subjective discount rates, the elasticity of the marginal utility of consumption, technology, population, and initial capital stocks. However, the rate of growth of every country eventually converges to zero. In the zero-growth steady state real interest rates differ across countries in so far as subjective discount rates differ.

In a world with integrated capital markets the real interest rate is 
determined by trie country with the highest marginal product of capical (assuming irreversible investment). Investment is first channeled to the country with the highest marginal product of capital, until its marginal product falls to the level of the country with the next highest marginal product. From then on investment takes place in both, maintaining equality of marginal products, which also determine the real interest rate. When the marginal product of capital in these two countries falls sufficiently to equal the marginal product in the country with the third highest marginal product of capital, the third country too begins to accumulate capital. And the process continues along the same line with other countries.

The above described process of capital accumulation determines output growth; i.e., GDP. Thus, for example, the country with the lowest marginal product of capital might not experience output growth for some time (or forever). Nevertheless, its consumption and GNP may be growing. Integrated capital markets lead to equalization of real interest rates. It is therefore evident from equation (1) that consumption of countries with subjective discount rates below the interest rate will be rising independently of their marginal product of capital. In particular, if they have identical preferences (i.e., common values of $\beta$ and $\rho$ ), consumption will grow at a common rate, converging eventually to zero. If subjective discount rates differ but $\beta$ is the same, the most patient country; 1.e., with the lowest discount rate, has the fastest growing consumption, and it ends up (in the limit) consuming the entire world output. Its consumption growth ceases when the real interest rate drops to its discount rate.

It is clear from this discussion that the neoclassical growth model fails to predict sustained long-run growth as a result of capital accumulation. One way out of this predicament is to introduce technical progress. Its 


\begin{abstract}
introduction as an exogenous process helps growth accounting, but is not satisfactory. In order to understand the evolution of economies along sustained growth trajectories and the role of trade in this process it is necessary to further explore the "unexplained residual" in growth accounting. If (1) is the basis of this inquiry, it is necessary to do away with the negative association between the real interest rate and the capital stock. One line of research in this direction, that has been explored by Romer (1986a,b) and Lucas (1985), breaks this link by introducing economies of scale. The essential elements of this approach are taken up in the next section.
\end{abstract}

\title{
3. Economies of scale
}

The idea that economies of scale can lead to a self perpetuating process of economic growth goes back to at least Allyn Young (1928). Romer's contribution lies in its precise formulation and linkage to neoclassical growth theory. One major obstacle to a precise formulation was associated with the usual difficulty to construct general equilibrium models with economies of scale. In each one of the clted papers he explores a route which is by now well known in the theory of international trade. The first is to consider economies of scale that are external to the firm but internal to the industry; the second is to consider economies of scale that are internal to the firm, with firms producing differentiated products and engaging in monopolistic competition. I will discuss both possibilities.

\section{A. External Economies}

External economies have been widely discussed in international trade theory (see Helpman (1984)). In the static models this takes the form of a 
production funcion in which the output level of an individuai firm depends or: its inputs and on the output level of the industry. This is usually zefered to as Marshalian externalities. The idea is that a larger industry supports larger industry specific public inputs, such as finer stages of specialization, thereby benefiting all firms. Following Arrow (1962), Romer shifted the externality from output to capital. Namely, the output level of an individual firm depends not only on its stock of capital, but on the stock of capital of the industry at large. In this context the stock of capital can be broadly interpreted to include human capital or knowledge. The precise interpretation dictates what would be reasonable assumptions about the production and accumulation technology, but is of no consequence for the points I wish to make here. Let us therefore maintain the interpretation of physical capital accumulation.

The production function of a single producer is taken to be $f(k, K)$, where $K$ is the economy's capital stock and $k$ is the capital stock of the producer (we suppress the share of labor that the producer employs in equilibrium). All producers are alike. Suppose also that there is a continuum of them, and that their measure is one. Then $k-k$ at each point in time.

A single producer takes the economy's capital stock as given. Therefore from his point of view the marginal product value of a unit of capital is $f_{k}(k, k)$. If a unit of output can be costlessly converted into a unit of capital, as we have assumed in the discussion of the neoclassical model, then the break-even condition for profitable investment (or the asset pricing equation) becomes

$$
\int_{t}^{\infty} e^{-[R(r)-R(t)]} f_{k}[k(r), K(r)] d r-1
$$


which implies

$$
r(t)=f_{k}[k(t), K(t)]
$$

It is clear that in this case accumulation of capital by individual firms drives down the real interest rate via the own capital stock effect, given the concavity of $f(k, K)$ in the first argument. Now, however, the real interest rate is also affected by the economy wide capital stock $K$ (with $K-k$ ), which represents the external effect. If an increase in the economy's capital stock raises the marginal product of capital of individual firms, capital accumulation raises the real interest rate via the external effect. The combined direct plus indirect effect of capital accumulation may therefore increase or reduce the real interest rate, depending on the nature of the production function. If $f_{k}(k, k)$ is rising in $k$, the interest rate increases; if it is declining, the interest rate falls. of particular interest for our purposes is whether the limit of the private marginal product of capital can be bounded above the subjective discount rate when the capital stock goes to infinity. If it is, there will be sustained long-run growth. The answer to this question is in the affirmative, as shown by the following example.

Let $f(K, K)-A K \log (1+k)$, where $A>0$ is a constant and $\log$ indicates the natural logarithm. The social production function, defined by $F(K)=f(K, K)$ exhibits increasing returns to scale, with the marginal product of capital increasing with the capital stock. The private production function $f(k, K)$ is concave in the private capital stock $k$, exhibiting declining marginal productivity of private capital. At each point in time the real interest rate is given by $f_{k}(k, K)-A K /(1+k)$ (see $(3 b)$ ). Since $k-k$ on the 
equilibrium path, the ime pattern of interest rates is

$$
r(t)-A \frac{k(t)}{1+k(t)}
$$

Hence, capital accumulation leads to rising real interest rates and rising growth rates. Given $k(0)$ a sufficiently large value of $A$ ensures $r(0)>p$. so that consumption grows from the very beginning, with its rate of growth rising over time until it reaches the long-run sustainable level $\beta(A-p)$.

This model with external economies of scale has two important general implications: first, the growth rate may be rising rather than falling; second, the economy may reach a sustainable positive long-run growth rate. It has also important Implications for a system of countries. In the absence of international capital mobility every country grows at its own rate, depending on preferences, technology, labor, and the initial capital stock. The larger the initial capital stock the higher the growth rate, because a larger capital stock brings about a larger marginal product of capltal. Growth rates do not converge necessarily to zero, and there may exist differences in the sustalned long-run growth rates.

In the presence of free international capital moblifty real interest rates are equalized. Consequently, consumption growth rates can differ across countries only in so far as preferences differ. This is similar to the result in neoclassical growth models. Here, however, investment takes a very different course. The real interest rate is determined by the country with the highest private marginal product of capital $f_{k}(k, K)$, and this is the country that attracts all investment as long as its private marginal product of capltal is the highest (the social marginal product of capital $F_{K}(K)=f_{k}(K, K)+f_{K}(K, K)$ is not necessarlly the highest in this country). If 
the private marginal product of capital is declining with the capital stock, taking into account both the direct and the external effects, then the real interest rate and the growth rate will be declining until the private marginal product of capital in this country falls to the level existing in the country with the next highest marginal product. If, however, the private marginal product is Increasing in the capltal stock via the joint direct and external effects, the real interest rate and the growth rate will be rising. In this case the gap in marginal productivities of capital never closes and investment is indefinitely channeled into a single country. It is now easy to see what happens when the marginal product falls in the highest marginal productivity country but is rising in the second highest, or in any other country down the line of the marginal productivity ranking. The first country down the line whose marginal private product of capital increases with the capital stock ends up accumulating capital for the world, provided its turn to invest is ever reached. Hence, there may exist agglomeration effects in capital accumulation. They may provide a significant advantage to countries that attract investment, thereby working in favor of large countries that have a large capital stock to begin with. This advantage is partly realized by means of returns to fixed factors of production, including labor (it is easy to calculate these advantages from the production function $A K \log (1+k)$ ). Hence, in this type of an environment it may make sense to pursue policies that stimulate growth, including the attraction of foreign investment.

In this formulation the production function is a black box. Particularly disturbing is the lack of explicit accounting for the external effects. It is, however, possible to imagine plausible situations in which the nature of the externality depends on the firms' conduct, on market structure, and the 1ike. Consequently, it is premature to draw policy conlusions from models 
that do not specify explicitly these relationships. Experience suggesis that the nature of useful policies depends on those unspecified links.

\section{B. Differentiated Inputs}

The second route to sustain sufficiently large real interest rates in the long-run, thereby ensuring long-run growth, is based on the notion of specialization refinements that was introduced by Ethier (1982). Ethier's original purpose was to provide a better foundation for his earlier work on international trade, in which he argued in favor of an external economy approach, but in which the output level of an individual firm depends on the size of the world's industry rather than the country's in which it is located. This was accomplished by constructing a model in which there exist differentiated intermediate inputs with which the final output is produced. These inputs are produced with economies of scale, with the market structure being monopolistic. Using a CES production function for the final good, productivity of the final good sector depends on the number of available middle products. In the context of international trade it makes the productivity level of a country's industry depend on the size of the world's industry when middle products are traded. A second benefit of this approach is that it underlines trade in intermediate inputs, which is indeed the bulk of world trade.

In the context of a growth model the production function of the final good can be written as

$$
y=A \int_{0}^{n} x(1)^{\alpha} \mathrm{di}, \quad 0<\alpha<1, \quad A>0
$$

where $n$ is the number (measure) of avallable intermediate inputs (stages of 
specialization) and $x(i)$ is the quantizy of variezy $:$ being empioved. Labor employment is being suppressed as before (it is part of the constant A). Given prices $p(i)$ for intermediate inputs in terms of the final good and $A=1$, profit maximization by producers of the final good yield the following demand functions for middle products:

$$
x(1)=\alpha^{1 /(1-\alpha)} p(1)^{-1 /(1-\alpha)}
$$

Now suppose that middle products are produced only with capital. The capital requirement for $x$ units of output of a single variety is $g(x)$, where average requirement $g(x) / x$ is declining over some range so as to exhibit economies of scale. Using the demand functions (5) monopolistic competition with free entry into the intermediate goods industry implies markup pricing over marginal costs as well as average cost pricing. Hence, if $r$ stands for the rental rate on capital these conditions yield

$$
\begin{aligned}
\alpha p(1) & =r g^{\prime}[x(1)], \\
p(1) & =r g[x(1)] / x(1) .
\end{aligned}
$$

Given $r$, (6) and (7) solve for prices and quantities. Clearly, all varieties are equally priced and produced in the same quantity. Taking also account of (5) provides a solution for $r$. Hence, (5)-(7) determine uniquely $(\mathrm{x}, \mathrm{p}, \mathrm{r})$.

Finally, assume as before that a unlt of the final good can be costlessly converted into a unit of capital. Then the interest rate has to equal the rental rate on capital, because the present value of the rental rates has to equal the cost of a unit of capital, which is 1 . Consequently, $r$ is the 
real interest rate and it is constant. If this technologically determined real interest rate is larger than the subjective discount rate the economy settles instantly on a fixed, positive, growth rate path. The rate of consumption growth equals the rate of growth of the capital stock, which equals in turn to the rate of growth of the number of intermediate inputs.

In a system of countries every country benefits from the opportunity to purchase intermediate inputs from its trading partners. If they have the same technologies, the rental rate on capital is equalized (see (5)-(7)), and so is the real interest rate, even if there is no international capital mobility. In this case there is no particular equilibrium investment pattern when capital markets are integrated; aggregate world investment can be distributed across countries in any feasible way. When capital markets are segregated savings of a country determine (as usual) its investment level. In both cases countries have common growth rates of consumption if preferences are also identical.

When production functions differ, there are richer dynamics. Suppose that only the technology to produce intermediate inputs differs across countries. Then from (5)-(7) it is seen that it w11l induce differences in output per variety, thelr price, and the rental rate. Differences in price will not eliminate the incentive to trade intermediate inputs, so that the statlc gains from trade will be realized. The effects of differences in rental rates depend on the degree of integration of financial markets. If there is no international capital moblitty, the rental rate of every country determines its domestic real interest rate and the growth rate of its consumption, capital stock, and the number of products (with the latter two being equal to each other). Every country settles immediately on a constant growth path. 
with integrated capitai markets the real interest rate is determined by the country with the highest rental rate on capital. Growth rates of consumption differ only if there are differences in preferences. Since the rental rates do not change through time (they do not depend on the capital stocks; see (5)-(7)), a country that begins with the highest rental rate maintains its position forever, thereby determining forever the real interest rate. This is also the country to which investment is channeled; it is in fact the only country with capital accumulation (unless there is more than one country with the highest rental rate) and the only country that introduces new varieties of middle products. The latter, however, are used worldwide.

A comparison of the two approaches outlined in this section reveals a great degree of similarity, as well as the suitable specification of the external effects suggested by Ethier. Consider for simplicity the case in which all varieties are equally priced. Then a producer who spends resources $z$ on producing the final good obtains an output level $y=A n(z / p n)^{\alpha}$ (see (4)). This output level exhibits declining marginal productivity in his resources $z$--which is analogous to declining marginal productivity of $k$ in $f(k, K)$. And it increases with $n$--which is analogous to the external effect K. The latter is even more evident when one recognizes that $n$ is proportional to the economy's capital stock. A special feature of the economy with intermediate inputs is that the private marginal product value of capital is independent of the capital stock. In a many country world $n$ is proportional to the world's capital stock rather than the country's in which the producer operates, provided intermediate inputs are traded. Therefore the external effect is not country specific but rather worldwide.

Finally, I would like to point out that the fixity of the rental rate in Romer's second model is a result of the specific functional form used in (4) 
rather than the model itself. This can be seen as follows. Let $q$ be the value of the integral on the right hand side of (4), and let the production function be $\phi(q)$. Then (5) is replaced by

$$
x(i)=\phi^{\prime}(q)^{1 /(1-\alpha)} \alpha^{1 /(1-\alpha)} p(1)^{-1 /(1-\alpha)} \text {. }
$$

Since a single producer of a varlety of intermediate input takes $q$ as given, this does not change the nature of (6) and (7). From (6) and (7), however, we obtain $a=g^{\prime}[x(1)] x(1) / g[x(1)]$, which fixes $x$ at the same level for every variety. Using this result together with (5a), (7), and the definition of $q$, we obtain $r-a x^{\alpha} \phi^{\prime}\left(n x^{\alpha}\right) / g(x)$. It is clear from here that the rental rate increases with $n$ if and only if $\phi^{\prime \prime}(q)>0$. In the original speciflcation $\phi^{\prime \prime}(q)=0$, which explains the constancy of the rental rate. Since $n$ is proportional to the capital stock (in fact, $n-K / g(x)$ ), we see that the rental rate can be increasing or declining in the capital stock, and when increasing it can reach a constant value as the stock of capital goes to infinity.

\section{Acautred Comparative Advantage}

So far I have dealt with aggregative growth issues, leaving little scope for the role of temporal trade. To be sure, intertemporal trade played a major role in this discussion, as is evident from the central role assigned to international capital mobility, which is the main channel of intertemporal trade. But what about the traditional form of trade; 1.e., the exchange of goods at a point in time? A study of the dynamics of this form of trade requires a disaggregated framework.

Early work in disaggregated frameworks concentrated on the effects of 
growth on tile terms of trade isfe Bhagwati $1958,:$. Ihis leac $=0$ ar. identification of conditions under which at constant prices capital accumulation or technical progress bring about an expansion of the export industry that exceeds the increase in local demand for its product. Under these conditions the terms of trade deteriorate. Later on, with the development of two-sector neoclassical growth theory, Onikl and Uzawa (1965) extended it to a two-country setup in order to study the effects of capital accumulation on the pattern of trade. Since they employed a framework without international capital mobility, capital accumulation of every country was driven by the propensity to save. Consequently, saving behavior determined the evolution of Hecksher-Ohlin comparative advantage. Work along these lines is surveyed by Findlay (1984) and Smith (1984), and its results are too well known to be repeated within the constraints of this paper. I proceed, therefore, to discuss a new line of research. There is, however, one point related to this approach that needs to be clarified at this juncture. In my discussion of the issues I pointed out that the extremely fast growth of exports in some of the NIC's gives the impression that international trade plays an important role in this process. It can nevertheless be argued that the comovement of output and exports stems from internal sources that bring about output growth, which induces in turn export growth. If this is the case, then causality is from trade to growth rather than the other way around. This argument, which is made in detall in Helpman and Trajtenberg (1987), proceeds as follows.

Suppose there is Hicks-neutral technical progress in the exporting industries. Then at constant prices it becomes relatively more profitable to produce exportables. Consequently, resources are driven from import competing industries to exporting industries. Factor rewards adjust to this 
reaijocaition in the usuai way. The resuit is that output of exportaies rises both because they employ more resources and because their production is more efficient. Since GDP rises while the import competing industries contract, output of exportables grows necessarily faster than GDP. As long as there is no particularly strong demand bias towards exportables when expenditure rises, exports are bound to grow faster than output. This explanation seems to be consistent with the data. Moreover, by introducing a spectrum of qualities for exportables it is possible to derive conditions on cost and price structures under which this process will also be accompanied by an upgrading of the quality of exports (as, for example, in Korea and Taiwan).

Our theoretical description fits the stylized facts. Is it the correct explanation? There is not enough evidence to form a final judgment. It is, however, my opinion that this is at best a partial explanation. For one thing it is necessary to explain why technical progress is concentrated in exporting industries. Is it just a coincident or is it after all the result of a mechanism in which foreign trade plays a major role? I tend to believe the latter. This suggests the need to explore alternative lines of research which are more explicit about productivity gains. Investigations of acquired comparative advantage are major candidates for this purpose.

Factor accumulation changes the degree of Heckscher-Ohlin type comparative advantage, and in a predictable way the pattern of trade (see the recent studies by Leamer $(1984,1987))$. However, many changes in world trade are probably associated with acquired comparative advantage, such as the development of new products, the development of new production technologies, learning to produce existing products, and the like. Therefore, important as factor accumulation might be, it cannot explain all changes in world trade. Recent work on international trade in the presence of economies of scale and 
noncompetizive narket structures, which was static in nature, provides a suitable point of departure for the study of trade dynamics with acquired comparative advantage.

The static theory emphasizes the role of differentiated products that are produced with economies of scale, and the importance for welfare of the available number of such products (see Helpman and Krugman (1985)). It is, however, clear upon reflection that the development of new products cannot be satisfactorily analyzed in static frameworks. A significant part of fixed costs in the production of specialized products is associated with their development and design, which takes up time and resources. Moreover, the fixed costs of R\&D are not recovered instantaneously but rather through sales over prolonged periods of time. This implies that the incentive to invest in R\&D depends on expectations of future profits, which depend in turn on the expected evolution of the industry (worldwide), the length of available patent protection laws, the speed of imitation by other countries (which also depends on their investment in reversed engineering and other forms of learning), and the like.

In order to take account of these complications it is necessary to construct explicit, dynamic models of international trade, in which R\&D is considered as an economic activity. Their study will help to understand the evolution of trade when acquired comparative advantage plays a central role. It should also shed new light on the process of economic growth and the relationship between trade and economic growth. As I indicated before, the link between trade and growth was traditionally analyzed by considering the effects of factor accumulation or technological improvement on trade. The new approach may illuminate the reverse causal link; from trade to growth. It should eventually also provide a suitable framework for a study of the role of 
economic poilicy in promoting acquired comparative advantagt and growth. Such policies have been widely discussed, and used to explain the success of some of the high performance countries (such as Japan and some of the NIC's). However, so far these arguments have been made without a suitable theoretical underpinning, and $i t$ is therefore difficult to evaluate their validity. Studies along the above suggested line should help to evaluate them.

An example of this line of theorizing is provided by Grossman and Helpman (1988). This work is limited is scope and incorporates only a few of the above listed features. It is, however, more complete than other studies in its detailed outline of dynamic economic forces. Of particular interest for our purpose is the treatment of R\&D. Suppose that there exists an industrial sector that produces horizontally differentiated products. Preferences are of the Spence-Dixit-Stiglitz type and there exists a continuum of such products. There exists a technology for product development, which is represented by a cost function $c_{n}(w)$, where $w$ is a vector of factor prices. An entrepreneur who incures these costs at a point in time obtains in return the know-how to produce a variety of the industrial product. This variety is unique, in the sense that no one else knows how to produce it. In principle it is possible to as sume that this variety-specific knowledge is limited in time, or that the time of acquired monopoly power is uncertain, and it is possible to link it to patent laws and imitation activities of other entrepreneurs (possibly from other countries). These complications are avolded by assuming that a developer gains indefinite monopoly power for his product.

Under these circumstances it pays to develop a product if the present value of operating profits derived in the future is at least as high as current R\&D costs. Competitive entry ensures that entrepreneurs break even in present value terms. Namely, 
(2c) $\quad \int_{t}^{\infty} e^{-i R(\tau)-R(t) !} \pi(\tau) d \tau-c_{n}[w(t)]$.

where $\pi(t)$ are operating profits at time $t$. This is the counterpart of the asset pricing equations (2a) and (2b). Choosing $R \& D$ as the numeraire, $c_{n}[w(t)]-1$ at all time periods. Then (2c) implies

$$
r(t)-\pi(t),
$$

i.e., the real interest rate--measured in terms of R\&D value--is equal to the instantaneous operating profit rate.

Next, if a share $s_{x}$ of total spending is allocated to industrial goods, then in symmetrical equilibria the instantaneous profit rate can be shown to equal $(1-\alpha) s_{x} E / n$, where $\alpha$ is a parameter of the utility function over differentiated products, which has the form given in (4); $E$ is total spending; and $n$ is the number of avallable varieties. The expenditure share is taken to be constant due to a Cobb-Douglas specification of upper-tier preferences for different product categories, whose number is assumed to be two. The second is a traditional good. Assuming a unitary elasticity of substitution in consumption over time implies that aggregate consumption expenditure $E$ (on both product categories) satisfies (1) with $\beta-1$. Taken together all this yields a differential equation in spending

$$
\frac{\dot{E}}{E}-(1-\alpha) s_{\times} \frac{E}{n} \cdot \rho .
$$

For the competitively produced traditional product price equals marginal costs while for the differentiated product, whose production takes place under 
constant returns to scaie after it is developed. price is marked up ajove marginal costs in the usual way. In addition there are factor market clearing conditions. All these static relationships enable one to solve prices, factor rewards, and output levels as functions of the spending level E. In particular, the level of R\&D--as measured by the number (measure) of newly developed varieties-is a function of expenditure;

$$
\dot{\mathrm{n}}-\nu(\mathrm{E}) \text {. }
$$

Equations (6) and (7) constitute an autonomous system of differential equations, which together with the initial condition on the number of products and the transversality condition from the consumer's decision problem yleld a unique equilibrium trajectory for a closed economy. Provided suitable stability conditions are satisfied, an economy that begins with a small number of products will experience a rising number of products and consumption expenditure. It will, however, reach a steady state with constant consumption and a constant number of products.

In this model the number of products plays the role of a capital stock; all investment is channeled into R\&D which leads to the accumulation of more and more variety. The accumulation process ceases when the profit rate-.and with it the interest rate--drop to the level of the subjective discount rate. From this point of view it is similar to the neoclassical model. The reason for this similarity is further revealed by considering a one-sector representation (which is close in spirit to Romer's, although quite different in implications). Suppose there is no traditional good. Then $s_{x}-1$. Suppose also that available factors of production can produce a fixed quantity $Q$ of a resource that can be used for product development or the production of 
differentiated products. Let one unit of the resource develop a single variezy and let $a$ units of the resource be required to manufacture a unit of the final good. Then the market price of the resource is 1 (remember that $R \& D$ is the numeraire) and the price of the final product is 1 for all varieties (the markup condition implies that price is a times marginal costs). In this case (7) reads

$$
\dot{n}-Q-E \text {, }
$$

which is the usual saving-investment relationship. In this form the model reduces to a variant studied by Judd (1985), although in a somewhat different representation. It makes clear why growth ceases; the profit rate and with it the interest rate, have to fall. But it also makes clear what is required for sustained growth; accumulation of variety is not enough to maintain indefinitely sufficiently high profit and interest rates. The introduction of new products squeezes profits. Accumulation of productive resources is required to prevent profit rates and interest rates from falling to the subjective discount rate.

Grossman and Helpman consider a two-country, two-good, two-factor version. The two factors are interpreted to be unskilled labor (or just labor) and human capital. The traditional good is the most labor intensive. Preferences are the same everywhere and so are technologies, which are of the constant coefficients type. Financial capital is mobile internationally. Within a wide range of endowment structures there is factor price equalization at each point in time. The wage rate is rising and the return to human capital is falling. The price of traditional goods is rising, while the price of manufactured differentiated products is rising slower, if at all (measured 
in eerms of the numeraire; $i . \in$. the fó activity). It is necessarily failing when manufacturing of industrial goods is more human capital intensive than R\&D. Otherwise it is rising. Investment in R\&D declines through time while output of manufactures increases. Output of traditional goods increases if and only if R\&D is more human capital intensive than manufacturing of Industrial goods.

The relatively human capital rich country runs a deficit on current account at the inftial stages of development (the world starts with zero variety). The rate of accumulation of new products is the same in both. Despite the existence of unbalanced trade, the human capital rich country is a net exporter of manufactures and an importer of the traditional good at every point in time. When $R \& D$ is more human capital intensive than manufactures, the volume of trade grows faster than consumption spending and also faster than GNP. Under the same relative intensity ranking a sufficiently large difference in factor composition brings about the emergence of multinational corporations in the human capital rich country. From this point in time the rate of product innovation is not the same in both countries and the human capital rich country may end up importing manufactures. Multinationals develop new products and locate manufacturing activities in the labor rich country (assuming that manufacturing requires labor while headqurter services require human capital). The degree of multinationality, as measured by the number of products produced by subsidiaries, their output volume, or their employment, increases initially and also close to convergence to a steady state. This seems to be a rich model, but not rich enough to account for all unexplained phenomena. Further extensions and elaborations are required.

Studies along this line can be helpful in explaining the role of acquired comparative advantage in the dynamic evolution of trade, in the process of 
econonic growti, and the interaction between them. Inis zype ct resea:ch is : its infancy, and it has to go a long way before its fuil potential is realized. Time will tell how large is this potential.

\section{Product cycles}

In the previous section countries were treated symmetrically and it was assumed that product developers maintain indefinite monopoly power. The latter assumption excluded the possibility of imitation which is at the heart of the product cycle approach. Also at the heart of this approach is an inherent asymmetry between the North, which knows how to develop new products, and the south that knows only how to imitate their production. Vernon's (1966) original insight was formalized by krugman (1979) in a framework with differentiated products, and recently generalized in various direction by other authors. I will provide a brief description of Krugman's approach in order to discuss its potential and the need to merge it with the approached outlined in the previous section. Following this discussion I will point out additional variations that are of potential interest.

Preferences for varlety are the same as in the previous section, but there is only one product; manufactures. Only the North acquires the know-how to produce new varieties and this is achieved at no cost (this is a critical and deficient assumption). The exogenous rate of innovation is 1 , so that $i$ times $n$ is the number (measure) of newly introduced products at a point in time, where $n$ is the number of products available in the world economy. At a point in time northern producers maintain monopoly power in $N$ varleties, while southern producers know how to produce ns varieties, with $n=n_{N}+n_{S}$. These numbers are determined as follows. The South tries to imitate production of varieties in which the North has monopoly power. At 
Each point in time it iearns how to produce a proporzion $\mu$ of goods ir. which the North has monopoly power. This too is costlessly achieved (another deficient assumption). In this case $\dot{n}_{S}-\mu \eta_{N}$ and $\dot{n}_{N}-i n-\mu \eta_{N}$. Namely. the number of products which the South learns how to produce equals the rate of imitation $\mu$ times the number of products in which the North maintains monopoly power while the addition to the number of products in which the North maintains monopoly power equals the overall addition to avallable variety minus the number of products whose production technology is acquired by the South. Denoting by $s_{N}$ the share of products in which the North maintains monopoly power this calculus Implies

$$
\dot{s}_{N}-1-(1+\mu) s_{N} .
$$

This is a differential equation that describes the evolution of product composition. If the initial value of the share is smaller than $1 /(1+\mu)$ the share rises over time until it reaches the steady state value $1 /(1+\mu)$. If it is larger, it declines towards the steady state value. In the steady state it is equal to the rate of innovation divided by the rate of innovation plus the rate of imitation. The larger the rate of innovation and the smaller the rate of imftation the larger the share of products in which the North maintains monopoly power in the long-run. This makes, of course, sense.

So far I have described the mechanics of product innovation and imitation. These mechanics have simple and sensible properties, but little economic content. Some economic content is added by the following considerations. Suppose that goods are produced only with labor, with one unit of labor producing one unit of any variety, and that initially the wage rate is higher in the North. There is perfect competition in the South. Then 
the South wili produce ail goods for which it has the required know-how: namely. $n_{S}$. The North will produce all goods in wich it maintains monopo:y power. Given the suitable pricing and market clearing conditions this implies the following equilibrium relationship between relative wages and the share $s_{\mathrm{N}}$

$$
\frac{w_{N}}{w_{S}}-\alpha\left(\frac{s_{N} L_{S}}{\left(1-s_{N}\right) L_{N}}\right)^{(1-\alpha)} .
$$

where $L_{f}$ is the labor force in country $f$. It is clear from here that if the share $s_{N}$ is rising the gap between northern and southern wages widens over time and if it is declining the wage gap narrows down. This is an important insight. 2 In the steady state the wage ratio is higher the larger the rate of product innovation and the smaller the rate of imitation. This too is a sensible result.

This model has been extended by Dollar (1986) to allow for two factors of production and for the rate of imitation to depend on the production cost differential between North and South. Another variant, due to Jensen and Thursby (1987), makes the rate of innovation depend on resources devoted to $R \& D$, but assumes that all the innovation is done by a single northern monopolist. It seems to we that future research will benefit from an integration of the approach presented in the previous section with the product

2In the latter case the wage gap may disappear before a steady state is reached, which will eliminate the identification of the number of products produced in the South with the number of products it knows to produce. This minor point can easily be taken care off. For current purposes suppose it does not arise: 
cycle mode1. By this I mean to endogenize the race of innovation and the race of imitation by means of explicit economic considerations that consist of an intertemporal cost-benefit analysis. Surely, the rate of imitation depends on resources devoted to reversed engineering, learning, and the like. The incentive to engage in this activity depends on expectations of future benefits, which depend. In turn on the degree of protection provided by patent laws and other devices by means of which monopoly power is preserved. Similarly for the rate of innovation. The incentive to engage in this activity depends on expected future proflts, which also depend on the above mentioned factors. It is therefore clear that the equilibrium values of these rates are interrelated in important ways, and they are jointly determined with other activities that draw on an economy's resources.

An alternative product cycle model has been proposed by Flam and Helpman (1987) (see also Segrstrom, Anat, and Dinopoilos (1987)). There horizontal product differentiation is replaced with vertical differentiation. Namely, goods differ in quality. Using a competitive structure they consider situations of labor growth (the only factor of production), changes in income distribution, and technical progress in manufacturing. The demand for different qualities of manufactured products is driven by differences in household incomes. Income distribution may differ across countries. They show that when the North has comparative advantage in the production of high quality products a quality based product cycle can emerge. Both North and South may be moving up the quality spectrum of produced goods, with the North introducing ever better products and the South abandoning production of lowest quality varietles. Moreover, as the North too abandons production of its lowest quality products, the varieties that were produced in the North are eventually picked up by the South and produced there until abandoned at a 
iater siage. Inis process explains ar ooserved phenomenon. various commodities are replaced over time with inigher quality products. and the lowest qualities disappear from the market.

It should be clear from this description that introduction of vertical differentiation carries great potential in the treatment of trade and growth. Kuch of the Increase in the standard of living has been achieved not so much by producing larger quantities as by providing higher quality products. By the same token much of International trade is an exchange of goods of different quality. It is most desirable to develop the theory along this line, paying explicit attention to the resource cost of higher quality product development and the incentive to engage in it. I will not repeat the arguments already made on this subject in reference to horizontal differentiation; they equally apply to vertical differentiation. The problem is, of course, that treatment of dynamic general equilibriun models with vertical product differentiation and noncompetitive market structures is much harder. Harder, yes, but not hopeless.

I have outlined a number of problems that require attention from international trade theorists, and which--I belleve--can also greatly benefit from careful empirical studies. I have also described some recent work, trying to highlight ways in which it can be used to shed new light on these problems. It appears that the way is now open for new inquires into the relationship between international trade and economic growth, and eventually, into the possible role of trade and industrial policy in the promotion of economic growth. 
References

Arrow, K.J., "The Economic Implications of Learning by Doing," Review of Economic Studies, 1962,24, Pp. $155-173$.

Baumol, W,J,., "Productivity Growth, Convergenece, and Welfare: What the Long-Run Data Show," Amertcan Economic Review, 1986, 76, Pp. 1072-1085.

Bhagwat1, J.N., "Immiserizing Growth: A Geometrical note," Review of Economic Studies, 1958, 25, pp. 201-205.

Foreign Irade Regimes and Economic Development: Anatomy and Consequences of Exchange Control Regimes, Lexington: Ballinger for the NBER, 1978.

De Long, B., "Have Productivity Levels Converged?" NBER Working Paper No. $2419,1987$.

Dollar, D., "Technological Innovation, Capital Mobility, and the Product Cycle in North-South Trade," American Economic Review, 1986, 76, Pp. $177 \cdot 190$.

Eithler, W.J., "National and International Returns to Scale in the Modern Theory of International Trade," American Economic Review, 1982, 72, Pp. $389-405$.

Feder, G., "On Exports and Economic Growth," Journal of Development Economics, 1982, 12, PP. $59-73$.

Findlay, R., "Growth and Development in Trade Models," in Jones, R.W. and Kenen, P.B. (eds.), Handbook of International Economics vol. I, Amsterdam: North Holland, 1984.

Flam, H. and Helpman, E., "Vertical Product Differentiation and North-South Trade," American Economic Review, 1987, 77, pp. 810-822.

Grilliches, 2., "Issues in Assessing the Contribution of Research and 


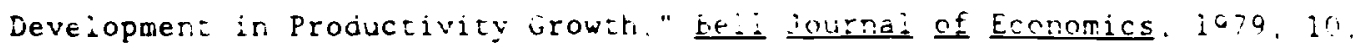
PP. $92-126$

Grossman, G.M. and Helpman, E., "Product Development and International Trade," mimeo, 1988.

Helpman, E., "Increasing Returns, Imperfect Competition, and Trade Theory," in Jones, R.W. and Kenen, P.B. (eds.), Handbook of International Economics vol.I. Amsterdam: North Holland, 1984.

and Krugman, P.R., Market Structure and Foreign Irade, Cambridge: The MIT Press, 1985.

— and Trajtenberg. M., "Dynamic Comparative Advantage and the Hypothesis of Export-Led Growth," mimeo, 1987.

Jensen, R. and Thursby, M. "A Decision Theoretlc Model of Innovation, Technology Transfer and Trade," Review of Economic Studies, 1987, 55. pp. $631-648$.

Judd, K.L., "On the Performance of Patents," Econometrica, 1985, 53, Pp. $567-585$.

Krueger, A.0., Forelgn Irade Regimes and Economic Development: Liberalization Attempts and Consequences, New York: Columbia University Press for the NBER, 1978 .

Krugman, P.R., "A Model of Innovation, Technology Transfer, and the World Distribution of Income," Journal of Political Economy, 1979, 87, pp. $253-266$.

Leamer, E.E., Sources of International Comparative Advantage, Cambridge: The MIT Press, 1984.

"Paths of Development in the 3-Factor, $n$-Good General Equilibrium Mode1," Journal of Political Economy, 1987, 95, pp. 961-999. 
Lucas, R.E. Jr., "On the Mechanics of Economic Development," mimeo, the Marshall and Horowitz lectures, 1985.

Maddison, A., Phases of Capitalist Development, Oxford: Oxford University Press, 1982 .

"Growth and Slowdown in Advanced Capitalist Economies: Techniques of Quantitative Assessment," Journal of Economlc Literature, 1987, 25, pp. $649-698$.

Michaely, M., "Exprts and Growth: An Empirical Investigation," Journal of Development Economics, 1977, 4, pp. 49-53.

Oniki, H. and Uzawa, H., "Patterns of Trade and Investment in a Dynamic Model of International Trade," Review of Economic Studies, 1965, 32, pp. 15-38. Pasinett1, L., Structural Change and Economic Growth, Cambridge: Cambridge University Press, 1981.

Romer, P.M., "Increasing Returns and Long-run Growth," Journal of Political Economy, 1986, 94, pp. 1002-1037..

- "Increasing Returns, Specialization, and External Economies: Growth as Described by Allyn Young," Working Paper No. 64, Rochester Center for Economic Research, 1986.

- "Capital Accumulation in the Theory of Long Run Growth," Working Paper No. 123, Rochester Center for Economic Research, 1988.

Smith, M.A.M., "Capital Theory and Trade Theory," in Jones, R.W. and Kenen P.B (eds.), Handbook of International Economics vol.I, Amsterdam: North Holland, 1984.

Vernon, R., "International Investment and International Trade in the Product Cycle," Quarterly Journal of Economics, 1966, 80, pp. 190-207.

Young, A.A., "Increasing Returns and Economic Progress," Economic Journal, 1928,38, pp. $527-542$. 